\title{
Microstructure and Mechanical Properties of Al-Mg-Si Hybrid Composites Reinforced with $\mathrm{SiC} / \mathrm{TiO}_{2}$
}

\author{
Dr.Israa A. Al.Kadir Hanan K. Azeez ${ }^{1}$ \\ ${ }^{1}$ Assistanat Professor, Department of production engineering and metallurgy, University of Technology, Baghdad, Iraq
}

\begin{abstract}
The aims of thiswork is to investigate the effect of adding different weight percents of $\mathrm{TiO}_{2}$ and $\mathrm{SiC} 1.5: 0,3: 0,4.5: 0,0: 1.5,0: 3$, $0: 4.5,1.5: 1.5,3: 3,4.5: 4.5$ particulate reinforcement on the mechanical properties andmicrostructure properties of base alloy AlMg-Si.By stir casting process, base alloy and hybrid composites were developed. By using stiffness and tensile measures, the mechanistic properties of the basic alloy and hybrid composites were calculated.The topography of fracture surfaces was inspected using the scanning electron microscope (ESM) and energy dispersive spectroscopy ( EDS). The findings shows, with a weight rise of $4.5 \%$ by the TIO2 / SIC up to $4.5 \%$, Improved absolute tensile power, strength of output and hardness. In contrast, the elongationrate is decreased, The optical microscope inspection shows that the particles in the matrix without any valves are distributed evenly. The X-Ray diffraction manifested the presence of different phases and intermetallic compounds $\mathrm{Mg}_{5} \mathrm{Si}_{6}$, $\mathrm{Mg}_{2} \mathrm{Si}, \mathrm{Al}_{2} \mathrm{O} 3, \mathrm{Mg}_{6} \mathrm{Si}_{3.3 .}, \mathrm{Al}_{3} \mathrm{Mg}_{2}$ and $\mathrm{Al}_{3} \mathrm{Ti}$.
\end{abstract}

Keywords

Vertex method, single composite, hybrid composite, mechanical properties

\section{Introduction}

The composites of the aluminum metal matrix have been extensively utilized in numerous sectors, including consumer devices, sports and the automobile industryDue to its best properties for corrosionresistant, low density, optimal thermal and electric conductivity, and improving precipitation strength the alloys are more active [1].Aluminum metal composites have either carbides or oxides in the aluminum matrix which have unique features, rather than the Al-alloys matrix (SAM), (SiC, ALN, B4C, TiC, Si3N4, TiO2, $\mathrm{TiO} 2$ ).Increased drift resistance, abrasion resistance, excellent strength and stiffness-to - weight ratios, and size stability are required[2]. Composites of aluminum matrix provide superior mechanical properties and wear power in contrast of steel, regardless of slipping intensity and load. This is primarily because the harsh particles like Al2O3, WC and SiC, etc, when dispersed into the matrix, limit and improve the temperature of the base alloys[3].

Most of the composite materials reinforced with particles by liquid metallurgy method (or so-called vortex method) have the advantage over the traditional techniques as simple, inexpensive, good binding to the matrix, more comfortable to control the composition of the mixture, flexibility, and application for larger production quantities. Numerous studies and researches have been published in this field. Ashok et al.[4] proved the best wear parameters of Aluminum6061-T6 reinforced by adding $15 \mathrm{wt} \% \mathrm{Al}_{2} \mathrm{O}_{3}$ and $15 \mathrm{wt} \% \mathrm{SiC}$ particulates having a particle size of $37 \mu \mathrm{m}$. The results represent that the incorporation of $\mathrm{Al}_{2} \mathrm{O}_{3}$ and $\mathrm{SiC}$ prefers to an increasing the erosion resistance of the hybrid compounds. Kenneth et al. [5] studied Al-Mg-Si's rice husk ash and silicone carbohydrate wear and corrosion component .Mixed in weight ratios 0:1, 1:0 1:3, 1:1, and 3:1 rices, ash and silicone carbide were also added.The findings demonstrate that the erosion tolerance of mixed composites is higher than the alloy $\mathrm{Al}-\mathrm{Mg}-\mathrm{Si}$ matrix that is just filled with silicon carbide.In addition, a corrosion resistance improved by 3.5 percent naphthon solution, enriched with rice peel and silicone carbide. Kataiah et al. [6] studied the effect of $\mathrm{TiO}_{2}$ with particles size $30-50 \mu \mathrm{m}$ additions by different weight percentage $0 \%$ to $20 \%$ on mechanical characteristics of $\mathrm{Al}-\mathrm{Mg}$-Si base alloy.The production of compounds using vortex methods. Results showed that the ultimate strength and hardness increased, but the flexibility decreased as the weight percentage of strengthening increased. Alaneme et al.[7] investigatedAl-Mg - Si alloy enriched with alumina and bamboo leaf ash (BLA) for corrosion and wear. The reinforcement powder consists of $0: 10,2: 8,3: 7$, and 4:6 theleaf ash of the bamboo and alumina weight percentage one after the other.The corrosion and wear test to assess the composite resistance in 3,5 NaCl solution. The wear of the single- and hybrid fiber, which has been researched using $25 \mathrm{~N}$, was used at $5 \mathrm{~Hz}$ level for 1,000 seconds. The results represent that the corrosion resistance of the composites decreased to $3.5 \% \mathrm{NaCl}$ when added BLA, but wear rates for hybrid composites with $4 \%$ BLA were shown to be higher than composites.

\section{Experimental work}


In this research, we used two types of particles ( $\mathrm{SiC}$ and $\left.\mathrm{TiO}_{2}\right)$ with particle size $(<75 \mu \mathrm{m})$ as a reinforcement phase embedded in $\mathrm{Al}-\mathrm{Mg}-\mathrm{Si}$ as a matrix phase, the table(1)Show alloy chemical composition. Figure (1)\& (2) represent the SEM and EDS examination of powders. The alloy Al-Mg-Si was made in an aluminum sink in the electric oven at temperature $700 \mathrm{oC}$ and then poured in $250 \mathrm{oC}$ into the prepared base alloy in the pre-heated steel mould. The composites have been prepared by stir casting method where the base alloy melted over a temperature of the fluid in an electrical furnace at $750{ }^{\circ} \mathrm{C}$.For homogenization chemical composition the fusion was held at this temperature for approximately $15 \mathrm{~min}$, then added flux(1\%wt.). In addition to a mechanical stirrer, gradually added reinforcement materials (silicone carbide and titanium oxide) have been added to the moulded alloy, which have been preheated with 1.5:0.3:0,4.5:0,0:1.5,0:3,0:4.5,1.5:1,5,3:3,4.5:4.5 wt percent by aluminum foil for 1 hour to remove humidity and to enhance stability by melting $\mathrm{Al}-\mathrm{Mg}-\mathrm{Si}$ alloy af, pre-heated to $550^{\circ} \mathrm{F}$. The wettability between base metal and reinforcement was increased by adding magnesia ( $1 \mathrm{wt}$ percent). Then grinding is carried out in the pre-heated mold and the composite material is filled with $\mathrm{SiC}$ and $\mathrm{TiO} 2$ pieces. After the preparation of all samples of the base alloy and composites, it has been done a machining process(turning) for castings according to the standard dimensions required for each test.

\section{Examinations and test}

\section{3-1 Microstructure examination}

The alloy cast and composite hybrid samples from Al$\mathrm{Mg}-\mathrm{Si}$ (15x10), is cut in measurements. By grinding and polishing, the samples were then grated with 1 \%HF.A metallurgical microscope with an Optical digital camera was used to study the microstructure for the preparations. Electron Microscopy Scanning and Spectrometer Energy Distribution (EDS)detector have been used type of (VEGA 3 LM)to research the topographical structure and the micro-chemical structure of reinforcements and tensile specimens. The resulting phases of basic alloy and composites have been tested for X-ray diffraction.

\section{3-2 Tensile test}

After being prepared as (ASTM E8) standard (figure 3 ), the tensile test was carried out using the machine Instron(DWD-200E) for the samples..

\section{3-3 Hardness test}

The Vickers research tester has been used for the calculation of strength of the base material and composites.The applied load was $(200 \mathrm{~g})$ for dwell time $(15 \mathrm{sec})$. And five readings of hardness value were taken in each sample to more accuracy.

\section{Results and discussion}

4.1 $\mathrm{SiC}$ and $\mathrm{TiO} 2$ additives influence on al-Mg-Si alloy microstructure alloy

The best uniform dispersion of ceramic reinforcement particles is the most important factor to achieve a homogeneous property of discontinuously reinforced composite material. Figure (4 to 7) Figure demonstrates the almost nodulous microstructure and distribution of it in the matrix in a business with particle coalescence throughout the grain boundaries and within the grain partly uniform. The contact between ceramic reinforcing particles and aluminum melt is anticipated to produce an interaction layer that enhances the wettability of the base alloy and ceramic particles. The interface between the metal matrix and strengthening in the base alloy reaction is extremely important because the high interfacial connection allows the load from the matrix to be transferred and distributed to the support.Figures (8 to17) highlighted findings for X-ray diffraction indicating the precipitation -Al phase and different intermetallic compound such as $\mathrm{Mg}_{5} \mathrm{Si}_{6}, \mathrm{Mg}_{2} \mathrm{Si}, \mathrm{Al}_{3} \mathrm{Mg}_{2}, \mathrm{Mg}_{6} \mathrm{Si}_{3 \cdot 3}$, $\mathrm{Al}_{3} \mathrm{Ti}$ and $\mathrm{Al}_{2} \mathrm{O}_{3}$.

\subsection{Tensile Test}

Figure 18 refers to the link between strengthening and yield strength, final strength and elongation in weight percentages. The ultimate strength and yield increased with the proportion weight of support, while the elongation rate fell.This nature because of attributed to the tight connection between particles and matrix of existence of hardened ceramic objects[9]. The X-ray showed the presence of different intermetallic compounds, such as $\left(\mathrm{Mg}_{5} \mathrm{Si}_{6}, \mathrm{Mg}_{2} \mathrm{Si}_{3.3}\right.$, $\mathrm{Al}_{3} \mathrm{Mg}_{2}, \mathrm{Mg}_{2} \mathrm{Si}$., $\mathrm{Al}_{3} \mathrm{Ti}$, and $\mathrm{Al}_{2} \mathrm{O}_{3}$ ). The differences in the matrix and ceramic particles in the thermal expansion coefficient led to the decrease in the density of the matrix[10].In going through the dislocations of the scattered particulates in a matrix, these particles are used as an obstruction to twisted base alloy because the high resistance inter-facial bonding process enabling process transmission between matrix and the active coherence between the reinforcing part and base alloy ( $\mathrm{TiO} 2$ and $\mathrm{SiC}$ particles).Also, the elongation decreases due to increasing brittleness of ceramic particles. Fig(19) highlights the fracture shape after the tensile test. Figures 20 to 29 display the fracture surface examined by elemental mapping using a 
scanning electron microscope. A bimodal array of dimples is primarily the fracturing surface of substances supported by $\mathrm{TiO} 3$ and $\mathrm{SiC}$ particulate matter. In the other hand, tenside composites fragmented in a fragile manner with no visible neck structure and a few good dicks are related to the ductile fracturing of the matrix.It could be because of the growth of the void nucleation, and coalescence occurred quickly. In addition, local tension concentration positions at the arming and matrix interface are responsible of the expression of a local crack activation and enhanced embrittlement effect.

\subsection{Hardness Test Result}

Fig(30)manifeststhe relation between basic alloy, composite and hybrid composite hardness values. The increased weight percentage of reinforcing particles as temperatures. Fig shows also that the composite hardness increases resistance to dislocation [11].The improvement in composite toughness is attributed to the strong hardening particles, to increase in resistance to localized plastic deformation because of dislocation impairments in particulate matter and because of the needle shaped $\beta$ "Mg2Si process which is also called the most effective hardening precipitate also, $\mathrm{Mg} 2 \mathrm{Si} 3.3, \quad \mathrm{Al} 3 \mathrm{Mg} 2, \quad \mathrm{Mg} 2 \mathrm{Si}, \mathrm{Al} 3 \mathrm{Ti}$ and $\mathrm{Al} 2 \mathrm{O} 3$ precipitated intermetallic solution[12, 13]. The reduction in the inter-particulate gap between hard $\mathrm{TiO} 2$ and $\mathrm{SiC}$ particles contributing to an rise in dislocation piles owing to introduction of more ceramic particles to the compounds. The great benefit of this dispersion strengthening impact is its durability even at high temperatures for long periods of time.Fig(28)demonstrated that silicon carbide composite reinforcement has a stronger hardness than tianium oxide composite because $\mathrm{SiC}$ is tougher than $\mathrm{TiO} 2$ and has a lower composition [13, 14].

\section{Conclusions}

1- Improve the base metal microstructure by incorporating titanium oxide and carbides in silicone particles where the arrangement varies approximately from dendrites to the configuration of the parallel axes. 2-With the weight of $\mathrm{TiO} 2$ and $\mathrm{SiC}$ additions decreased, the stiffness improved.

3-Additional voltage and power of $\mathrm{TiO} 2$ and $\mathrm{SiC}$ are rising by weight.

4- The elongation decreases for one and mixed compositeswith $\mathrm{TiO} 2$ and $\mathrm{SiC}$ increasing in weight percentage. grains of composite material are refined, has shown that composite hardness increases. The improvement in composite stiffness is attributed to its strong toughness, hence rising power by the Hall Petch equation, which represents The link between durability and the size of grain which obstructs the dislocation movement also demonstrates a higher hardness than the single composite in the composite hybrid.Resistance to locally deformed plastic is that due to the fact that particles are an obstacle to dislocations and that $\mathrm{Mg} 6 \mathrm{Si} 3.3$ is also known to be the most powerful intermetallic compound precipitate such as $\mathrm{Mg} 2 \mathrm{Si}, \mathrm{Al} 3 \mathrm{Mg} 2, \mathrm{Al} 3 \mathrm{Ti}$ and $\mathrm{Al} 2 \mathrm{O} 3$.The further pottery particles applied to the mixture, the greater the inter-particulate difference between $\mathrm{TiO} 2$ and $\mathrm{SiC}$ hard particles, the greater the dislocated row. One of the great benefits of this dispersal enhancing effect is its conservation even for long periods and high

[1] Kaka Ma, Enrique J .Laverina, and Julie M. Schenug. "Review of the effect of microcomponents by enhanced alloy matrix composites." Journal reviews advanced materials science (46), 91-10 (2017).

[2] Gapalakrishnan E, Busuna K, and Kayaraganam $\mathrm{P}$, "Experimental wear behavioural study of LM25 aluminum hybrid metal matrix composites of the same $\mathrm{SiC}$ and $\mathrm{TiO} 2$ volumes, Journal of materials and technology, 48(6),803-810 ( 2014).

[3] Saravanan .C, Subramanian. K, Ananda V, and Sunkara. R, "Effect of composites of enhanced particulate al-metal matrix" Journal Mechanics and mechanical engineering, 19 (1), 23-30 2015).

[4] Ashok Kr. Mishral, V.Kumar, and R.Kr.Srivastava,"Al-6061 T6-15 hybrid metal matrix composite technical efficiency enhancement with the Taguchi process and gray ties study"Journal of Minerals and Materials Characterization and Engineering,2,( 4), 351-361 (2014).

[5] Kenneth Kanayo Alaneme,T. M. Adewale andP.A.Olubambi,"Hybrid Al-M g-Si matrix composites reinforced by degradation and wear of husk ash and silicone carbide" Journal mater research technology, 1(3),9-16 (2014).

[6] Kataiah G.S, and Girish D.P, "Aluminum 6061$\mathrm{TiO} 2$ composite's mechanical properties and fractography" International Journal of pharmaceutical studies reserch,(1), Issue 1, July, September 17-25, (2010).

[7] Alaneme K.K,OlubambiP.A,Afolabi A.S, and Bodurin M.O, "Al-Mg - Si matrix of alloy composites in bamboo leaf ash and alumina with a temperature improved chloridinte and a rib application. " International journal 
electrochemical .science. (9),5663-5674, (2014)

[8] 8-(ASTM)E 8M - 00b, Analysis of metallic components conventional analytical techniques, An American National Standard, 2000, pp 6.

[9] Veeresh KumarG. B.,C.S.P.Rao, N. Selvaraj, and M. S. Bhagyashekar, "Al6061-SiC and Al7075Al2O3 composite product matrix studies" Journal of minerals and materials characterization and engineering,9(1),43-55 (2010).

[10] Kamal H, Azad Md, Redhewal A, and Sayena V, "Mechanical properties of al-based metal matrix composites improved by $\mathrm{SiC}$ and $\mathrm{Al} 2 \mathrm{O} 3$ ", Journalofengineering research and applications, "(5), Issue 9, part 2, Sep. 65-69, (2015).

[11] Saha S,Tareq SH and Galib RH, "The effect of aging in al-Si - Mg alloy on microstructures and mechanical properties," Journalof materialsciences and engineering,5( 5$),$ 1-4 (2016).

[12] Gyu .T.J, Ki.Y.K, Jung.H.M, Chul.L, WhiJ.K,andSuk.J.K, "Impact on the mechanical features of the automobile steering knuckle, created with modern casting method ", Metals, Vol,8, 857, 2,2018.

[13] GhaziJ.H.,"Impact on the mechanical properties of the AA 6061 aluminum alloy by reinforcing ceramic particles.," Engineering. and technologyJournal, 31( 14), 2611-2618 (2013).

[14] Lakshmanan P., and Jinu G.R, "Synthesis of magnesium-infused $\mathrm{TiO} 2$ particles by argoncontrolled casting and characterization" Journalchemical and materialsengineering, 5(2), 26-33 (2017).

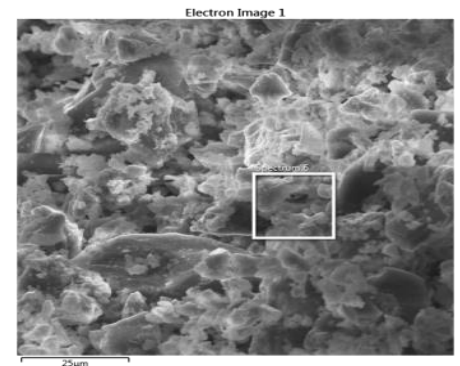

A

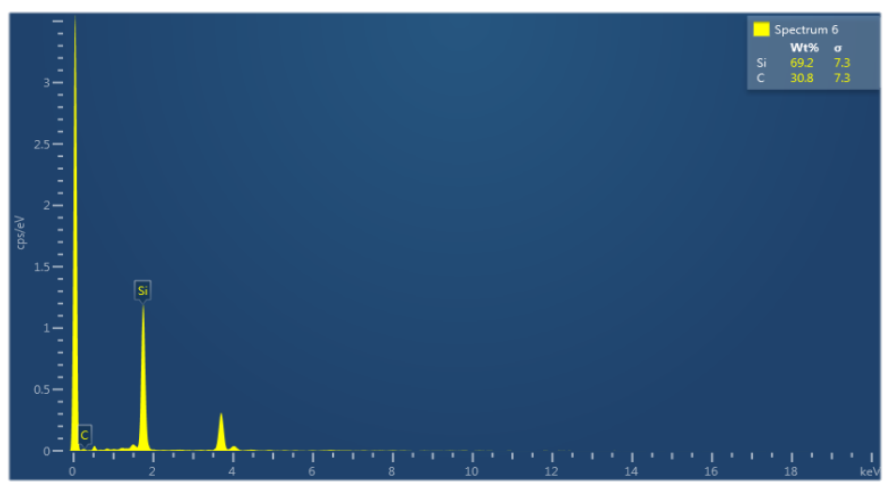

B

Fig (1):-SiCparticles, (A)E-microscopy scanning, (B) Spectrometer of energy dispersion

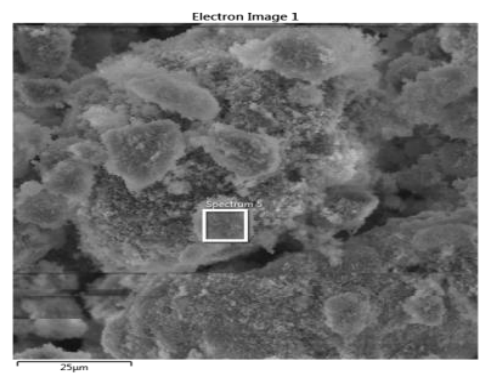

A

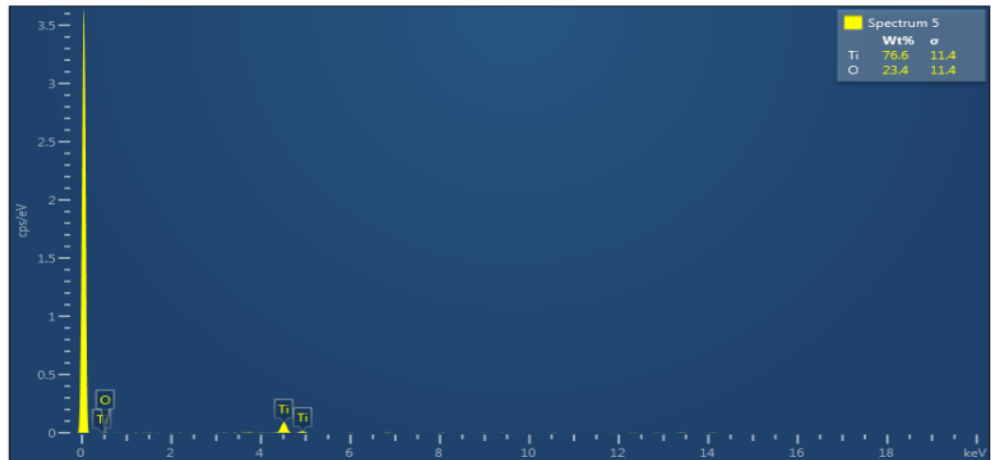

B

Fig( 2):- $\mathrm{TiO}_{2}$ particles,(A) E-microscopy scanning,(B) Spectrometer of energy dispersion

Table\{ 1\}Al-Mg-Si alloy chemical composition (wt\%). 


\begin{tabular}{|c|c|c|c|c|c|c|c|c|c|}
\hline Elements & $\mathrm{Si}$ & $\mathrm{Fe}$ & $\mathrm{Cu}$ & Mn & $\mathrm{Mg}$ & $\mathrm{Cr}$ & $\mathrm{Ti}$ & $\mathrm{Zn}$ & $\mathrm{Al}$ \\
\hline $\begin{array}{l}\text { Casting } \\
\text { alloy }\end{array}$ & 0.530 & 0.27 & 0.181 & 0.041 & 0.954 & 0.067 & 0.014 & 0.004 & $\mathrm{Bal}$ \\
\hline $\begin{array}{l}\text { Standard } \\
\text { alloy }\end{array}$ & $\begin{array}{l}0.4- \\
0.8\end{array}$ & $\begin{array}{l}\operatorname{Max} \\
0.7\end{array}$ & $\begin{array}{l}0.15- \\
0.4\end{array}$ & $\begin{array}{l}\text { Max. } \\
0.15\end{array}$ & $\begin{array}{l}0.8- \\
1.2\end{array}$ & $\begin{array}{l}0.04- \\
0.35\end{array}$ & Max.0.15 & Max.0.25 & $\begin{array}{l}95.8- \\
98.6\end{array}$ \\
\hline
\end{tabular}

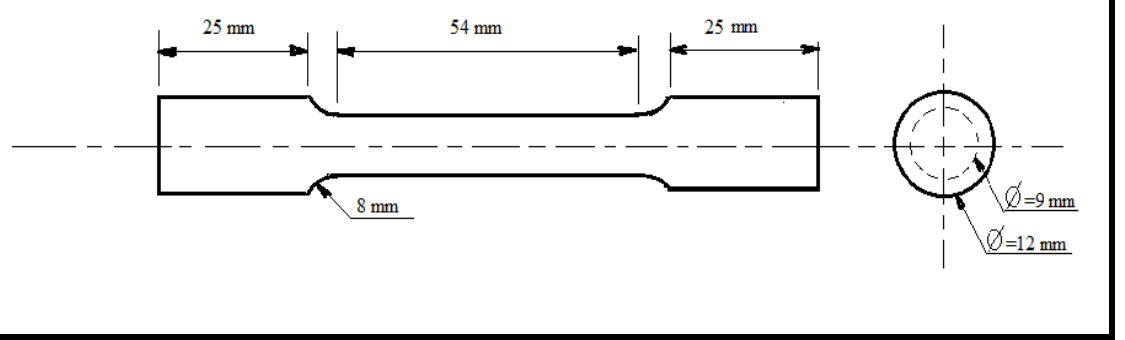

Fig (3) Standard of specimen of tensile test [8].

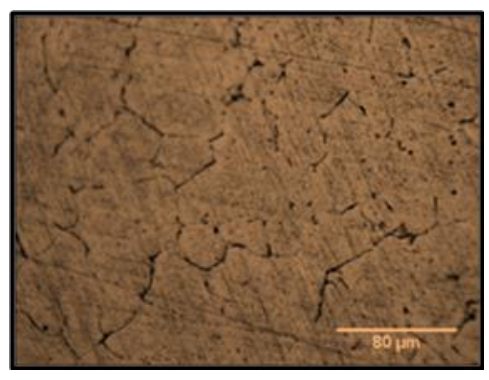

Fig(4)The microstructure of base alloy

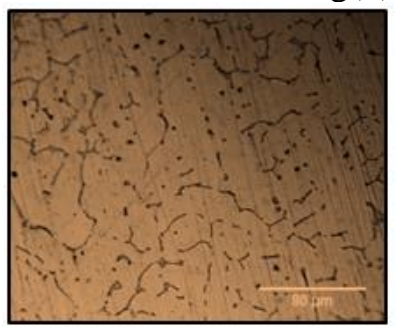

A

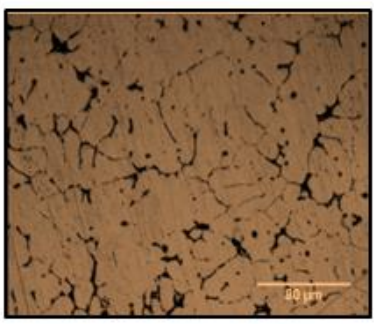

$\mathrm{B}$

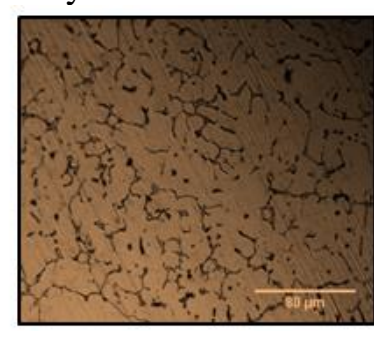

$\mathrm{C}$

Fig(5):-The microstructure of $(\mathrm{A})$ composite $1.5 \% \mathrm{TiO}_{2}$, (B) composite $1.5 \% \mathrm{SiC},(\mathrm{C}) 1.5 \%$ hybrid

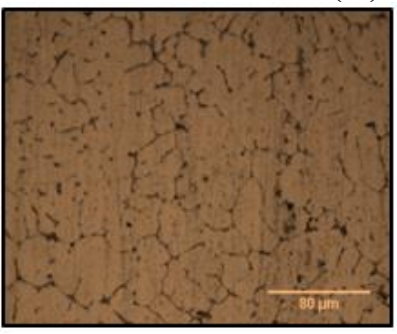

A

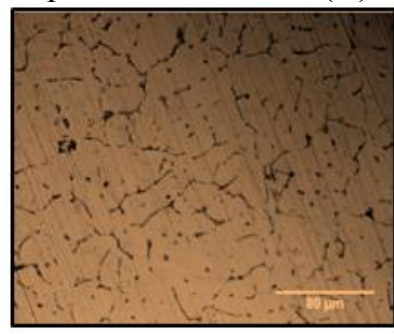

$\mathrm{B}$

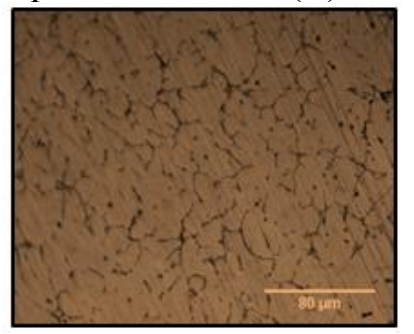

$\mathrm{C}$

Fig (6):-The microstructure of (A) composite $3 \% \mathrm{TiO}_{2}$, (B) composite $3 \% \mathrm{SiC}$, (C)3\%hybrid composite 


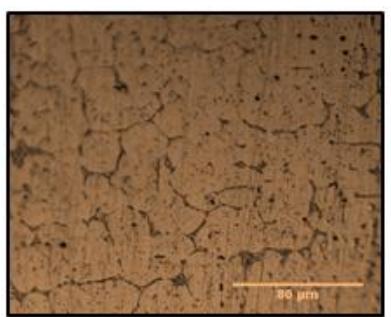

A

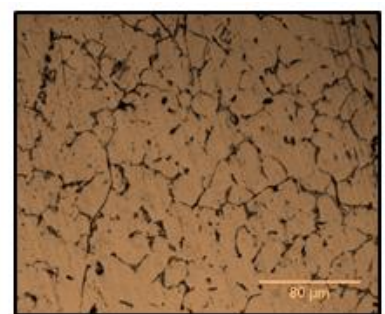

$\mathrm{B}$

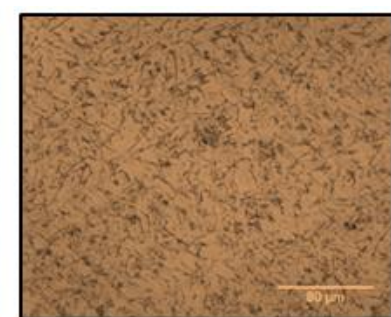

$\mathrm{C}$

Fig(7)The microstructure of $\{\mathrm{A}\}$ composite $4.5 \% \mathrm{TiO}_{2},\{\mathrm{~B}\}$ composite $4.5 \% \mathrm{SiC},\{\mathrm{C}\} 4.5 \%$ hybrid composite

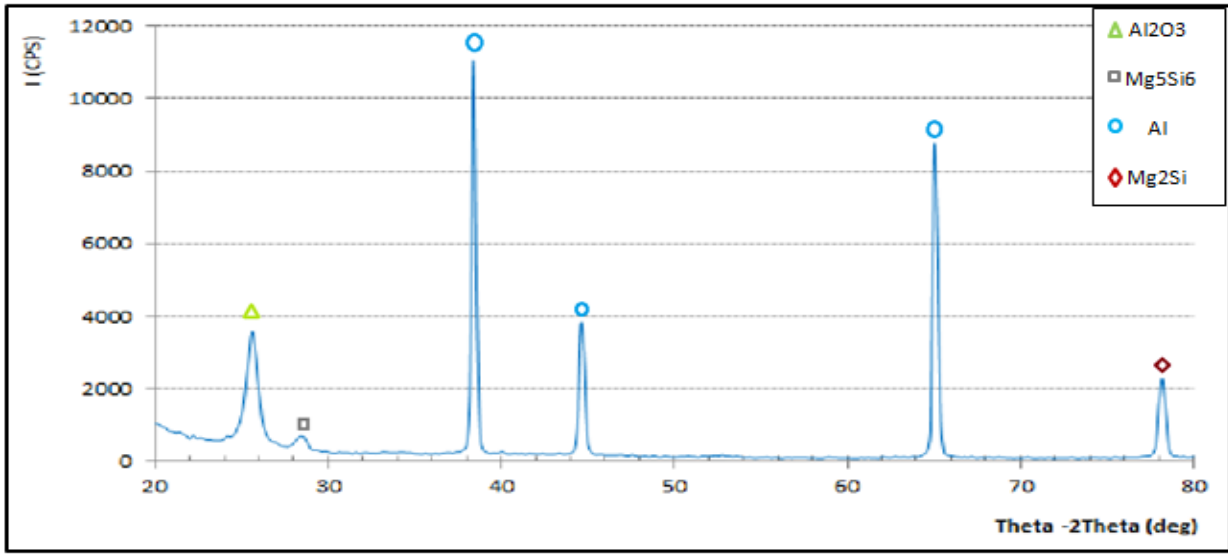

Fig(8) Diffraction from X-ray analysis of Al-Mg-Si alloy

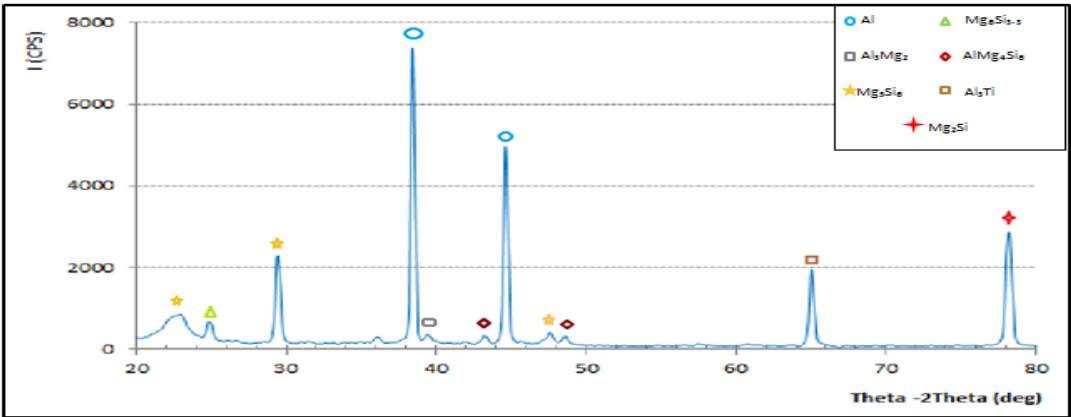

Fig(9)Diffraction from X-ray analysis of $1.5 \% \mathrm{TiO}_{2}$

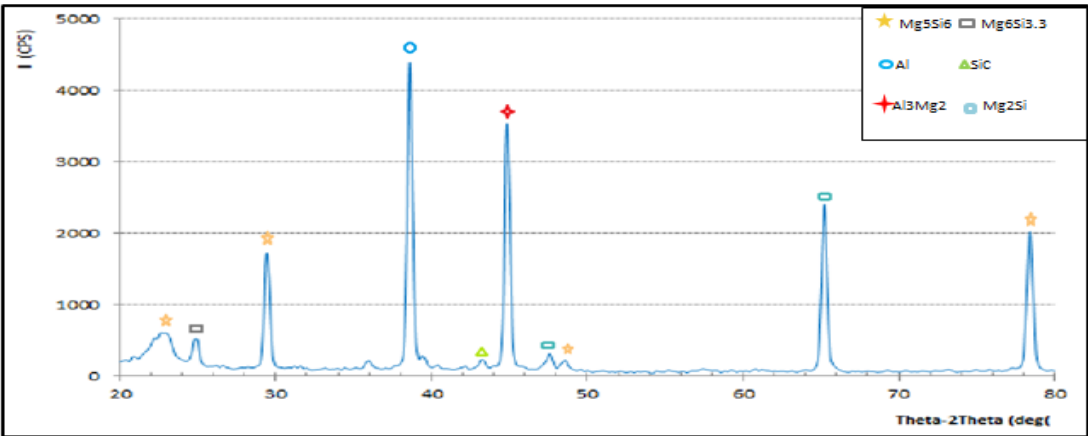

Fig(10)Diffraction from X-ray analysis of $1.5 \% \mathrm{SiC}$

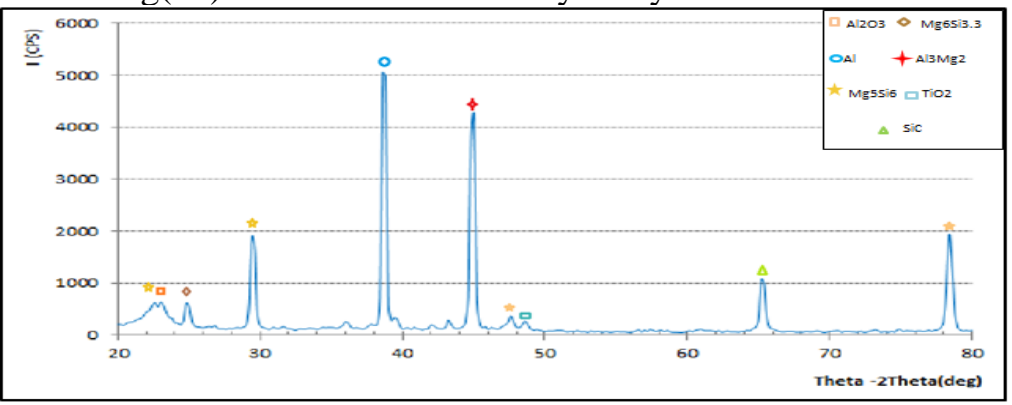

Fig(11)Diffraction from X-ray analysis of 1.5\%hybrid composite 


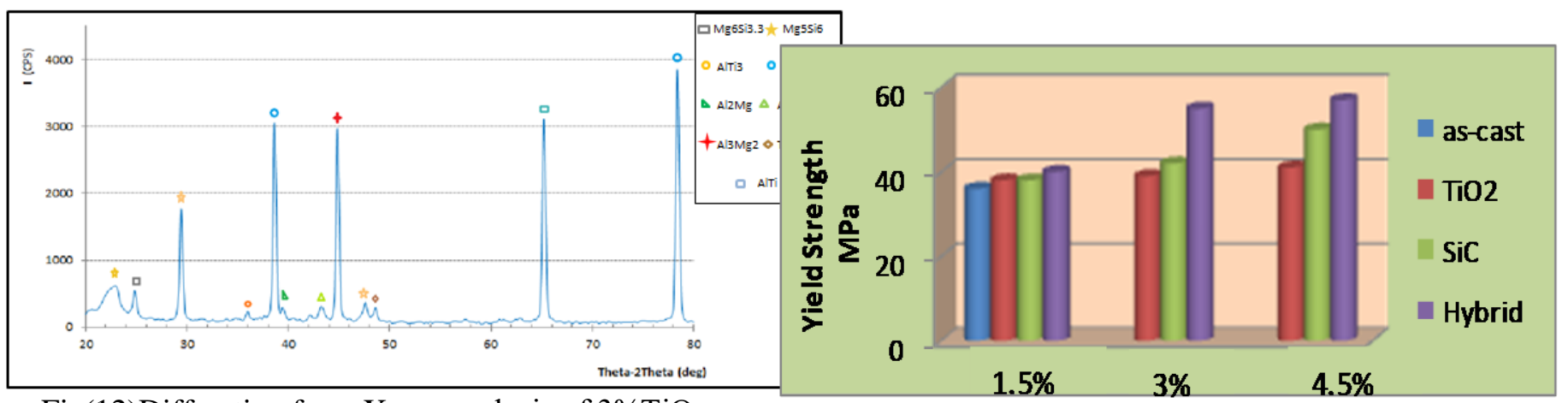

Fig(12)Diffraction from X-ray analysis of $3 \% \mathrm{TiO}_{2}$

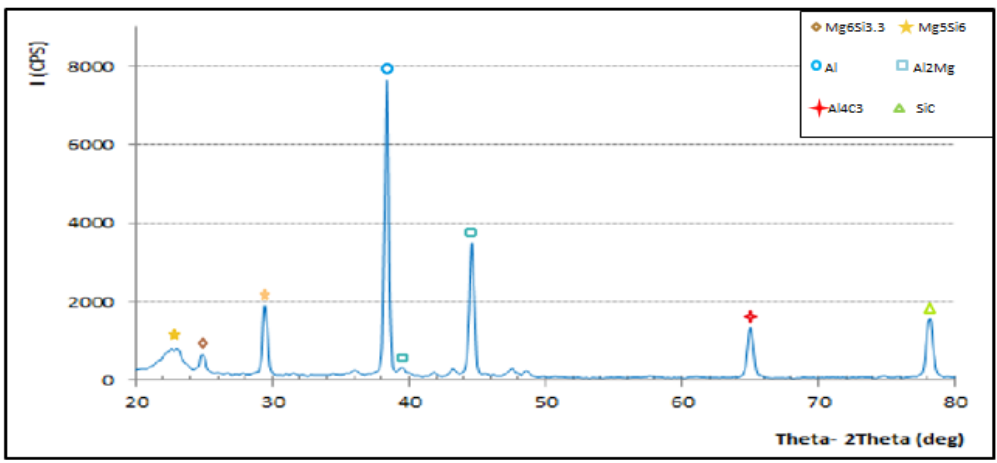

Fig(13)Diffraction from X-ray analysis of 3\% SiC

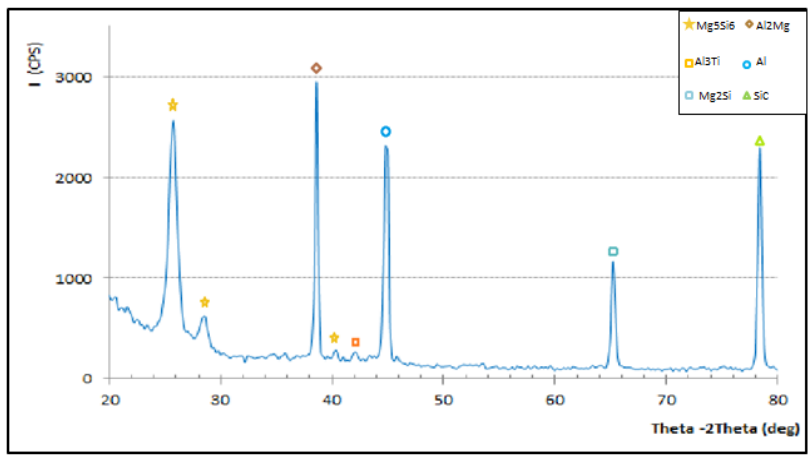

Fig(14)Diffraction from X-ray analysis of 3\%hybrid composite

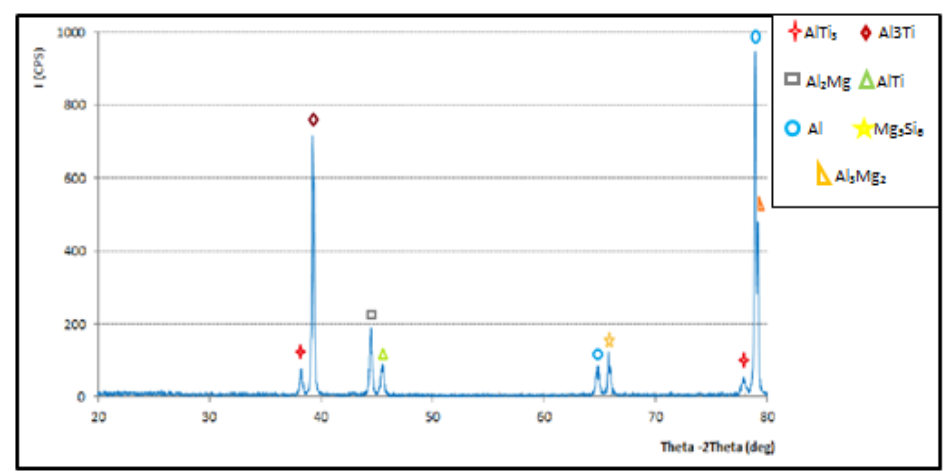

Fig(15)Diffraction from X-ray analysis of $4.5 \% \mathrm{TiO}_{2}$ 


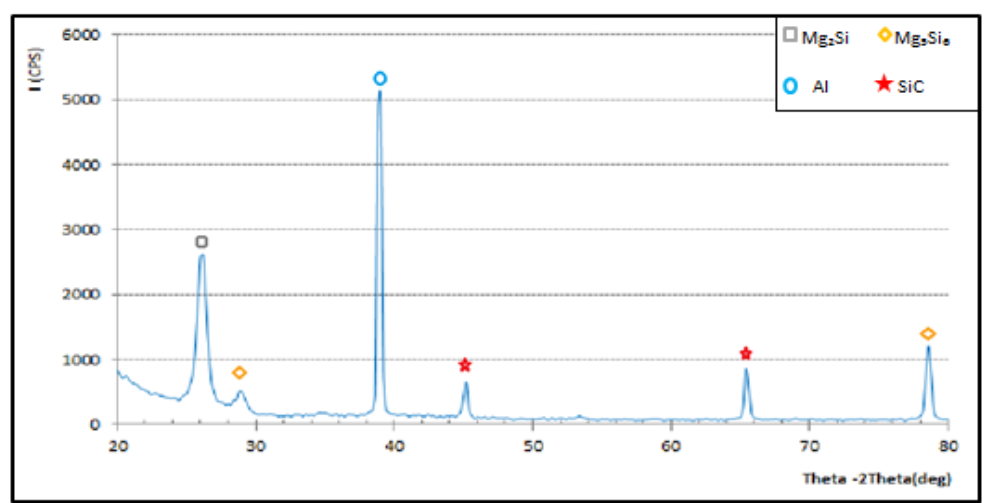

Fig(16)Diffraction from X-ray analysis of $4.5 \% \mathrm{SiC}$

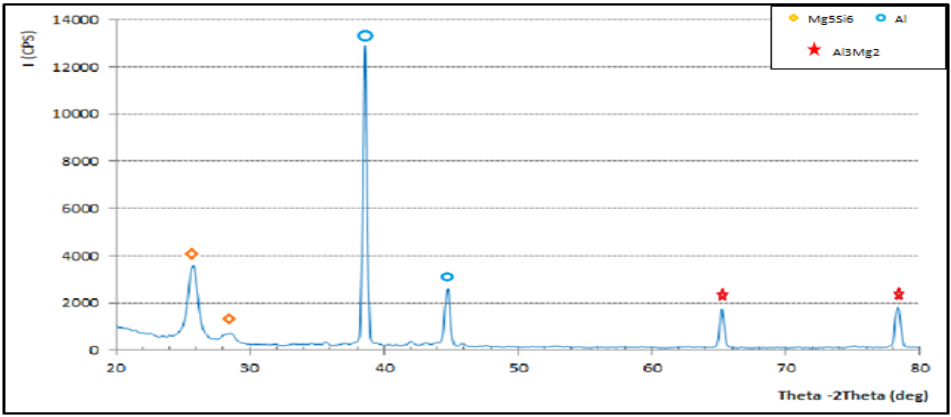

Fig(17)Diffraction from X-ray analysis of 4.5\%hybrid composite.

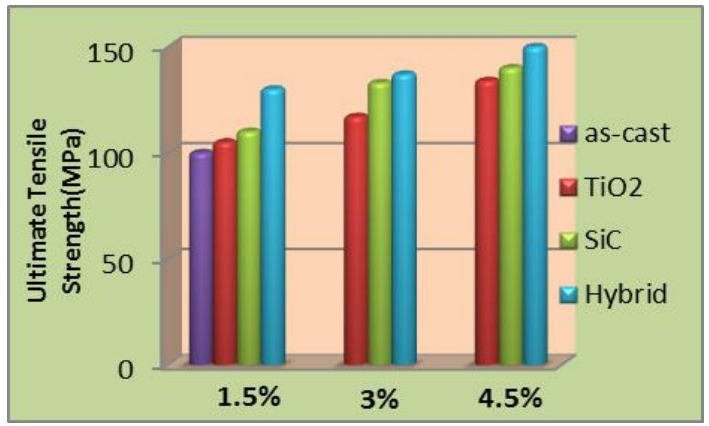

b

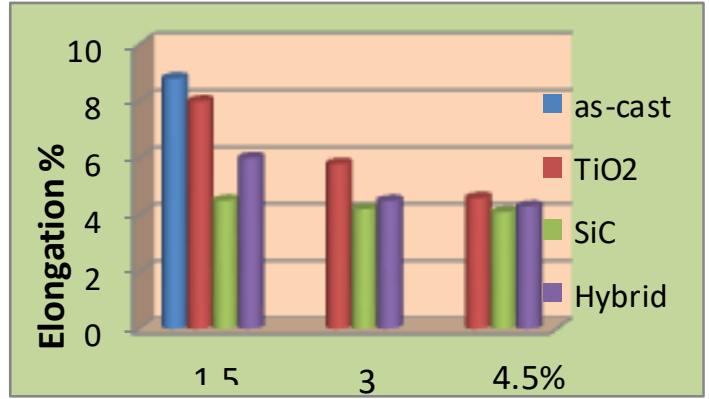


c

Fig(18) Relationship between, (a)Ultimate strength and weight percentage of reinforcement, (b) Yield strength and weight percentage of reinforcement, (c) Elongation and weight percentage of reinforcement

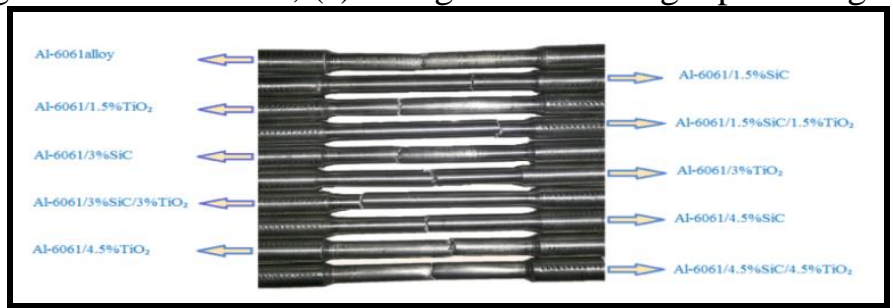

Fig(19) The samples after tensile test.
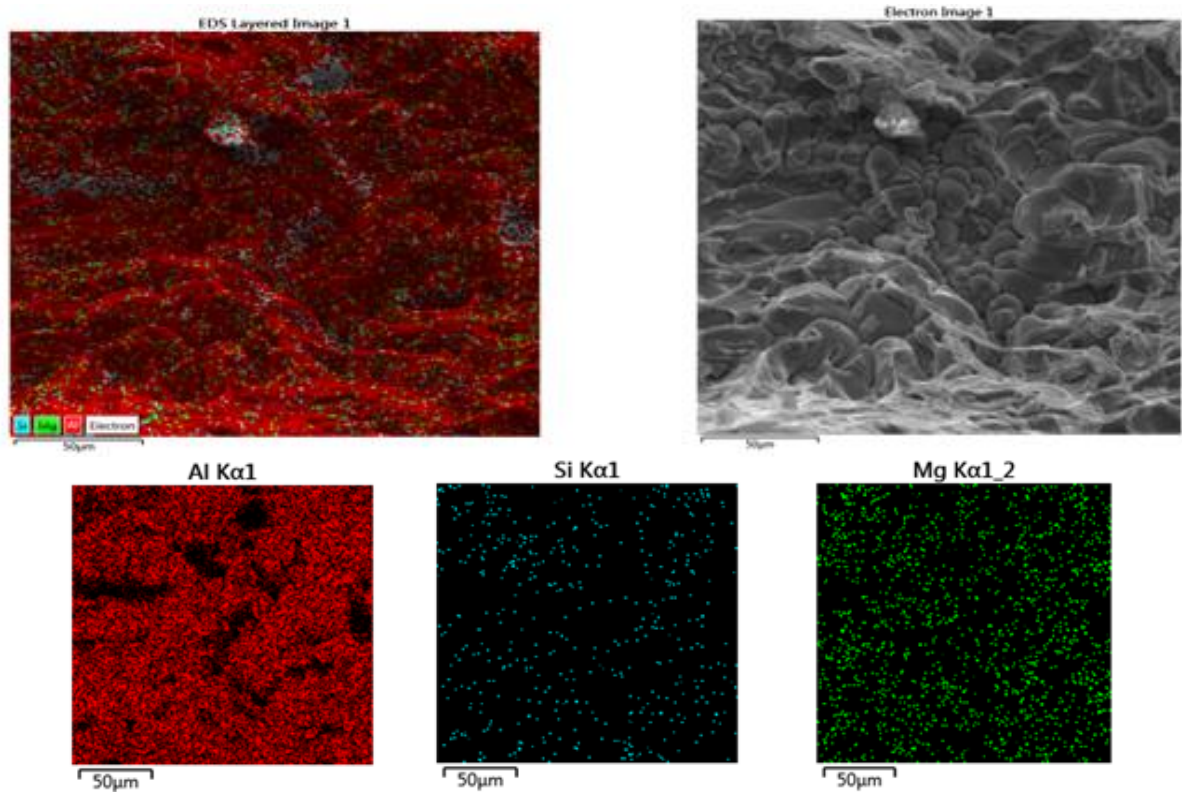

$\operatorname{Mg~K\alpha 122}$

Fig(20) the elemental mapping of Al-Mg-Si alloy by using SEM
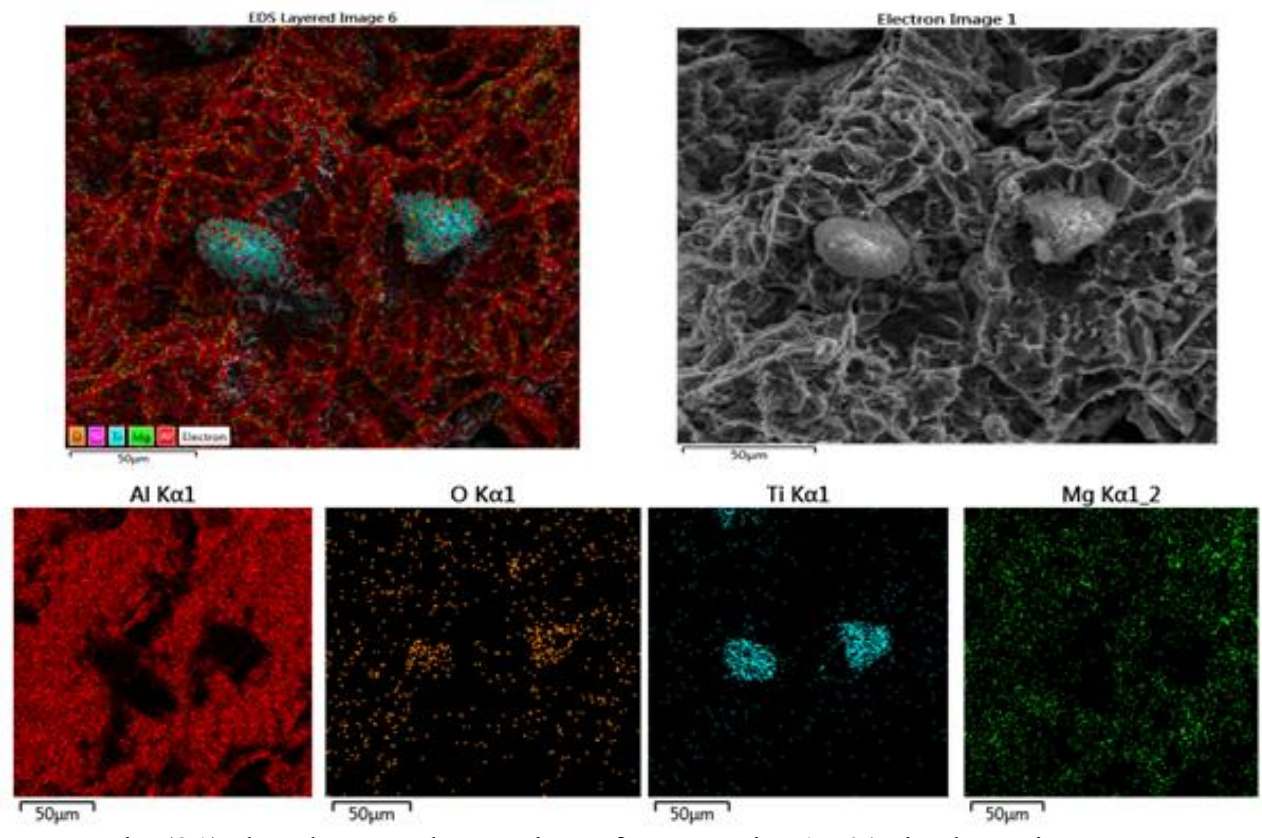

Fig (21) the elemental mapping of composite $1.5 \% \mathrm{TiO}_{2}$ by using SEM 

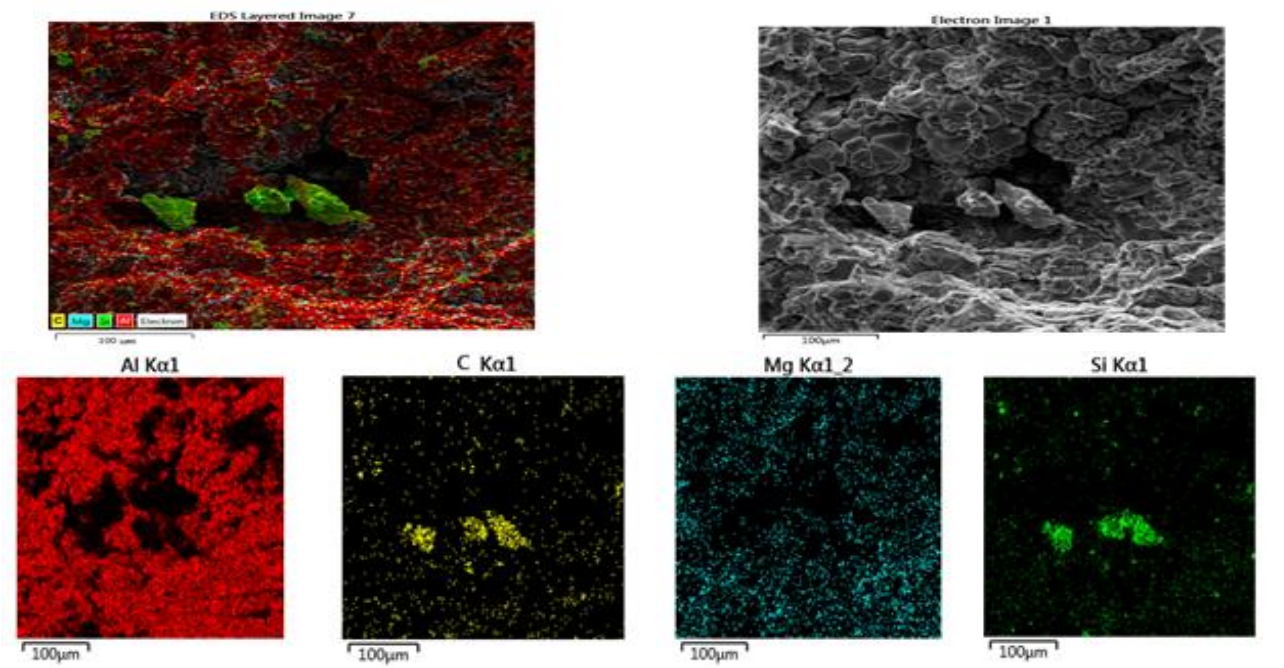

Fig (22) the elemental mapping of composite $1.5 \% \mathrm{SiC}$ by using SEM
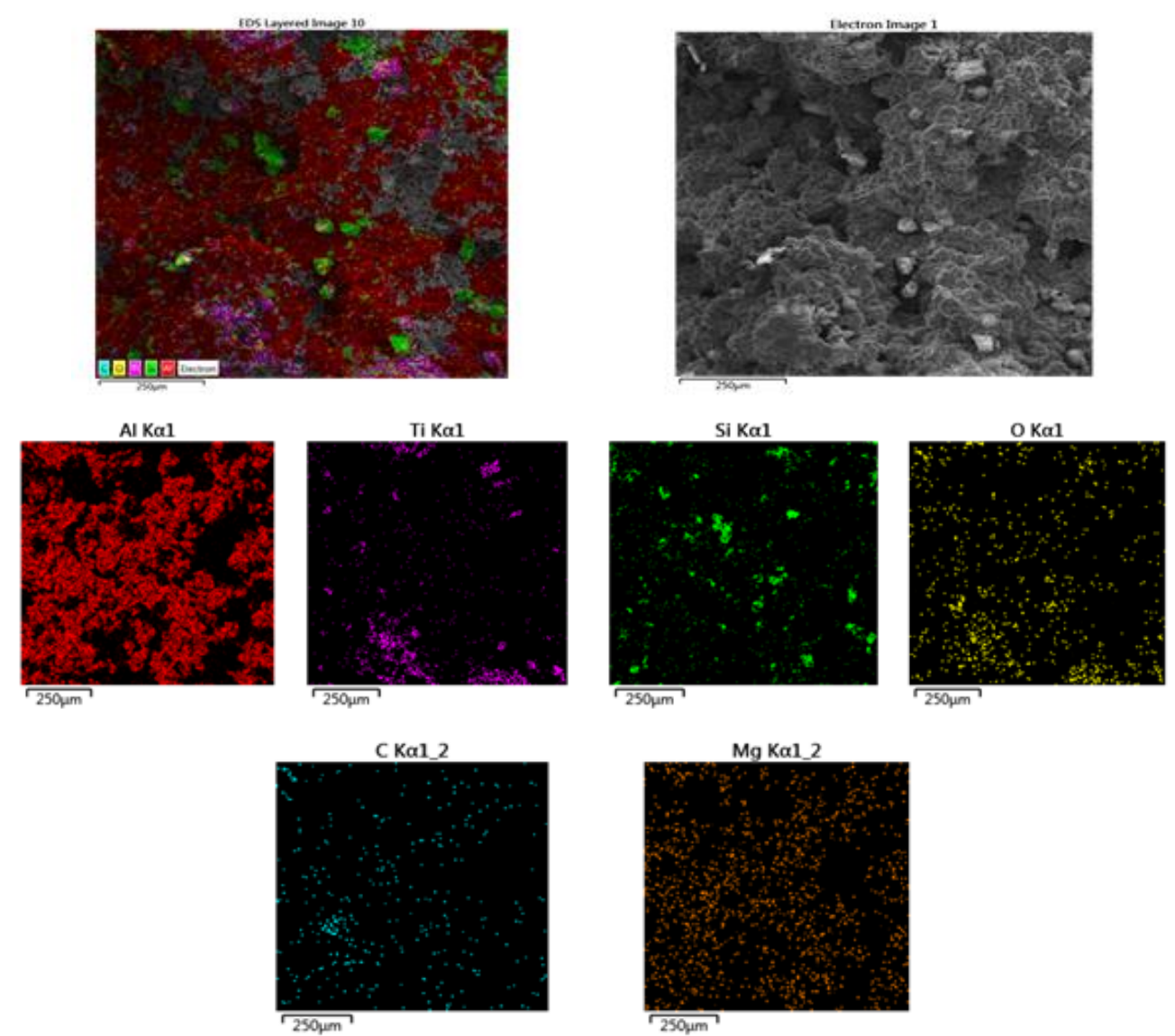

Fig (23) the elemental mapping of 1.5\%hybrid composite by using SEM
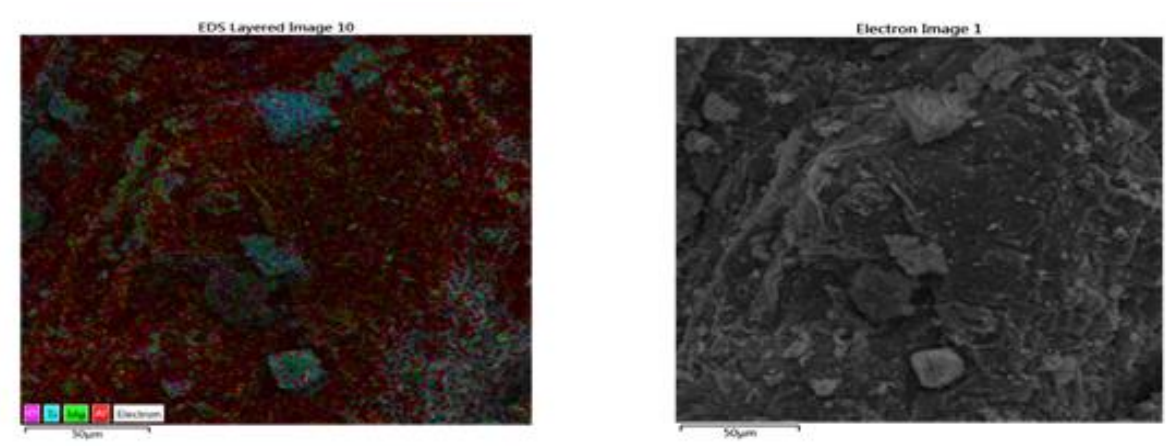

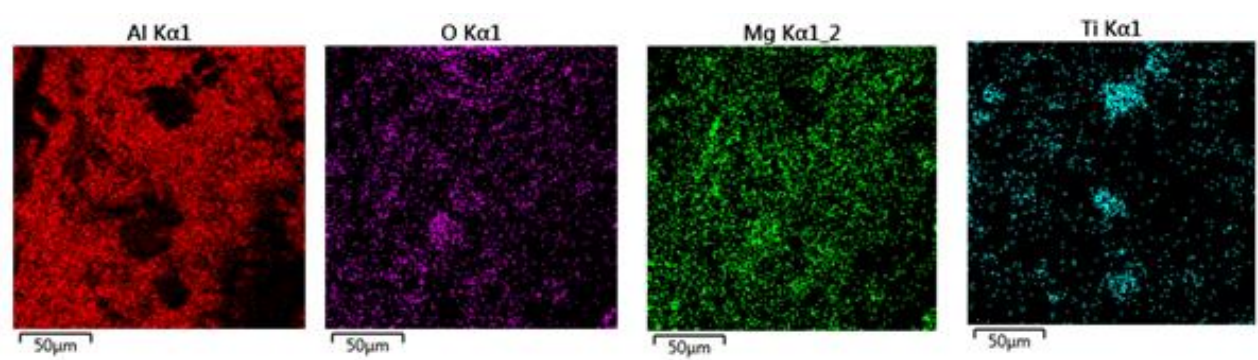

Fig(24) the elemental mapping of composite $3 \% \mathrm{TiO}_{2}$ by using SEM

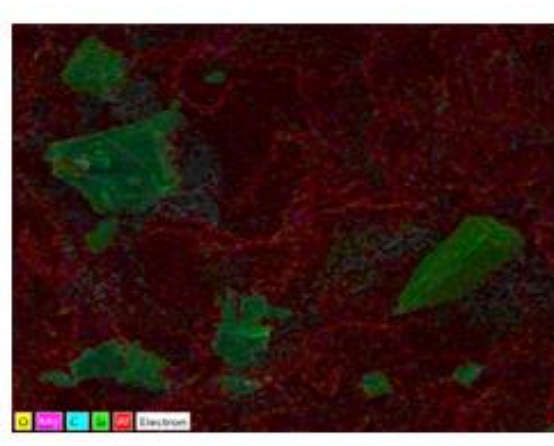

Al Kal
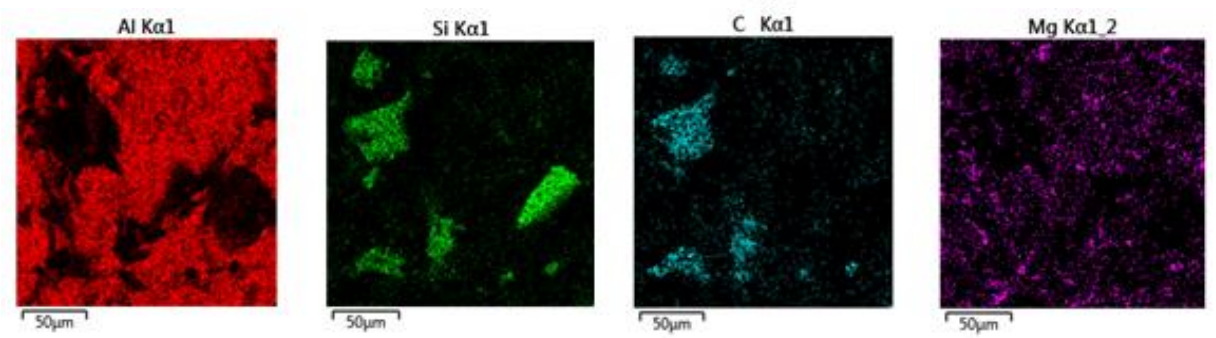

Fig(25) the elemental mapping of composite $3 \%$ SiC by using SEM
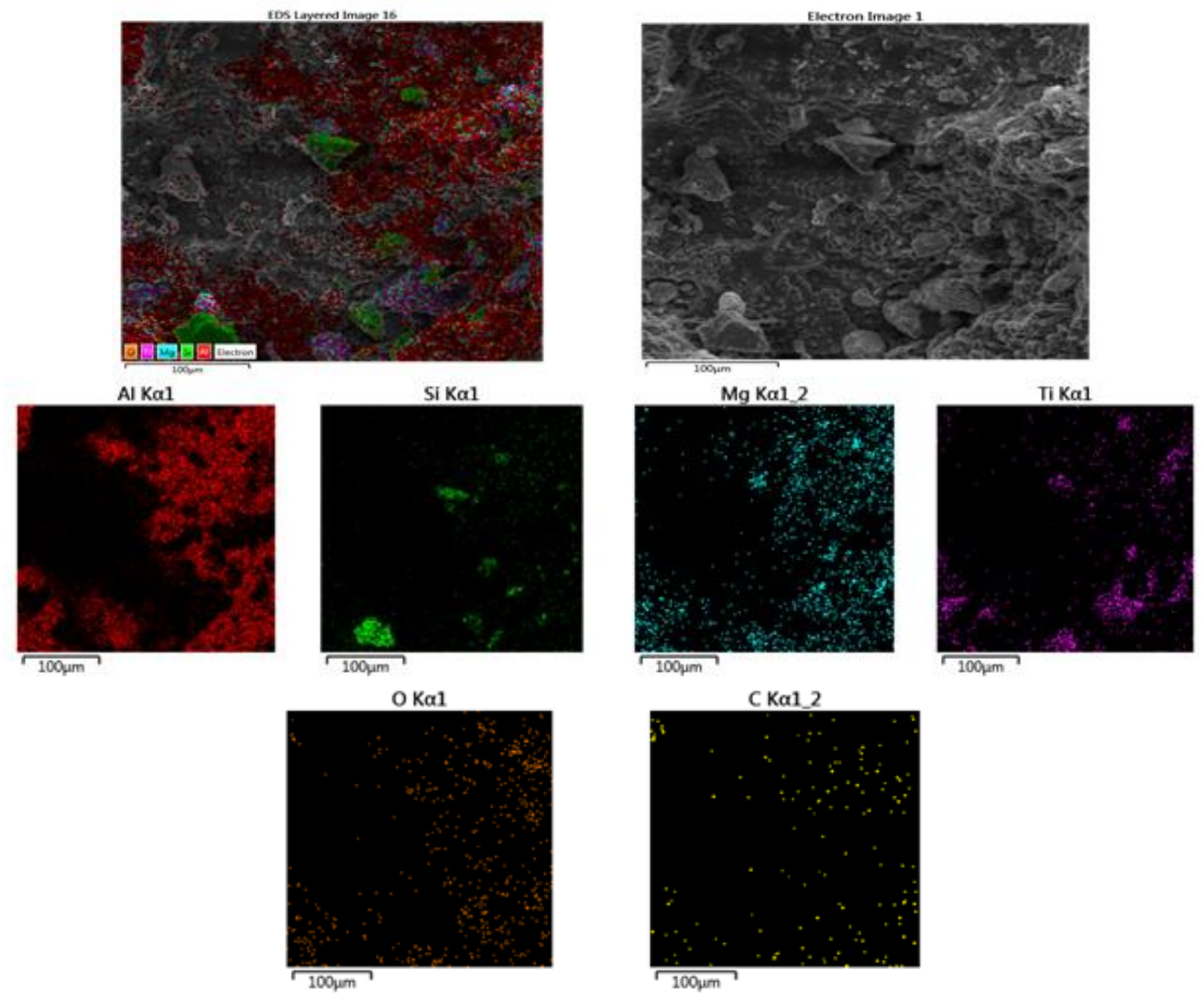

Fig (26) the elemental mapping of 3\%hybrid composite by using SEM 


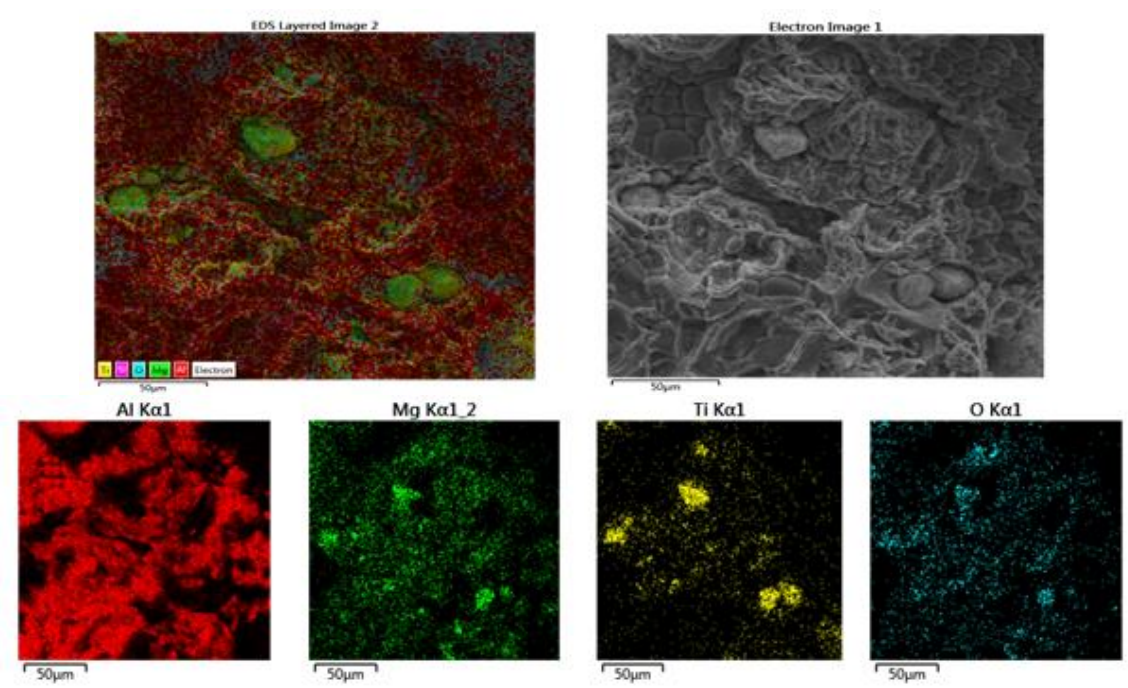

Fig(27) the elemental mapping of composite $4.5 \% \mathrm{TiO}_{2}$ by using SEM
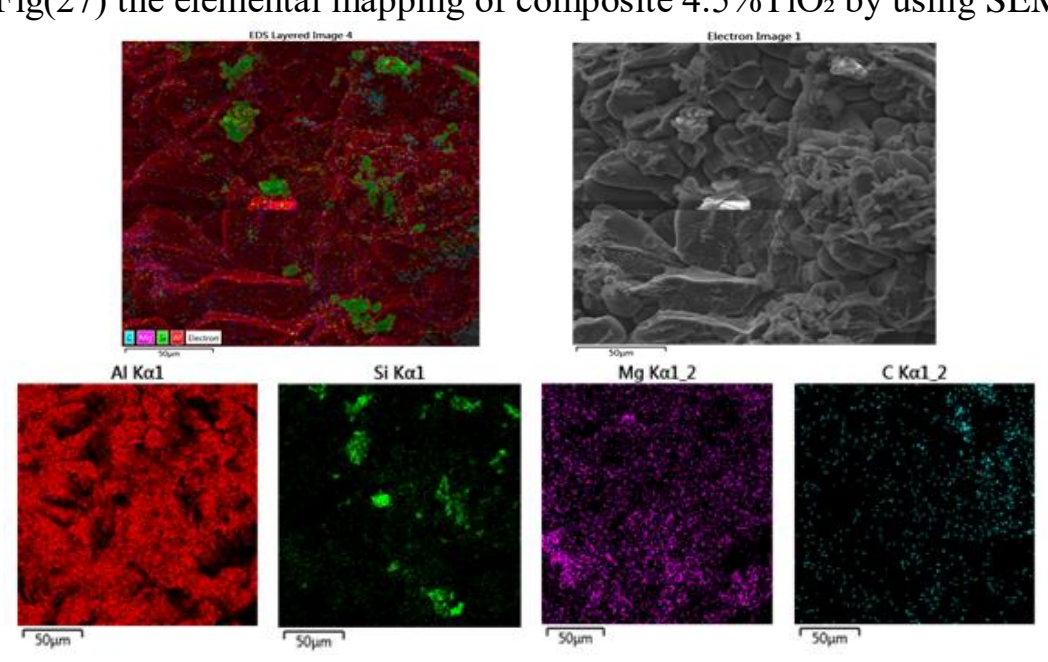

Fig(28)the elemental mapping of composite $4.5 \% \mathrm{SiC}$ by using SEM
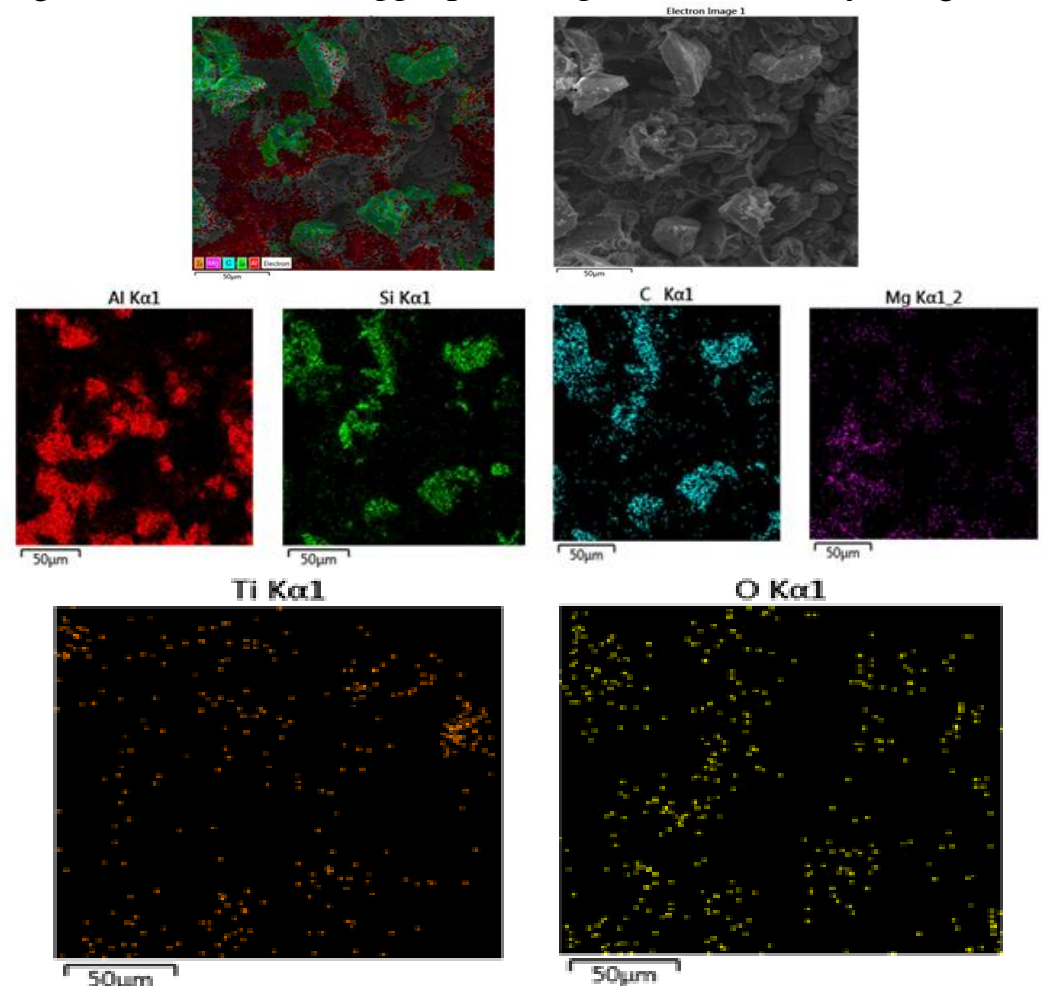

Fig(29)the elemental mapping of $4.5 \%$ hybrid composite by using SEM 


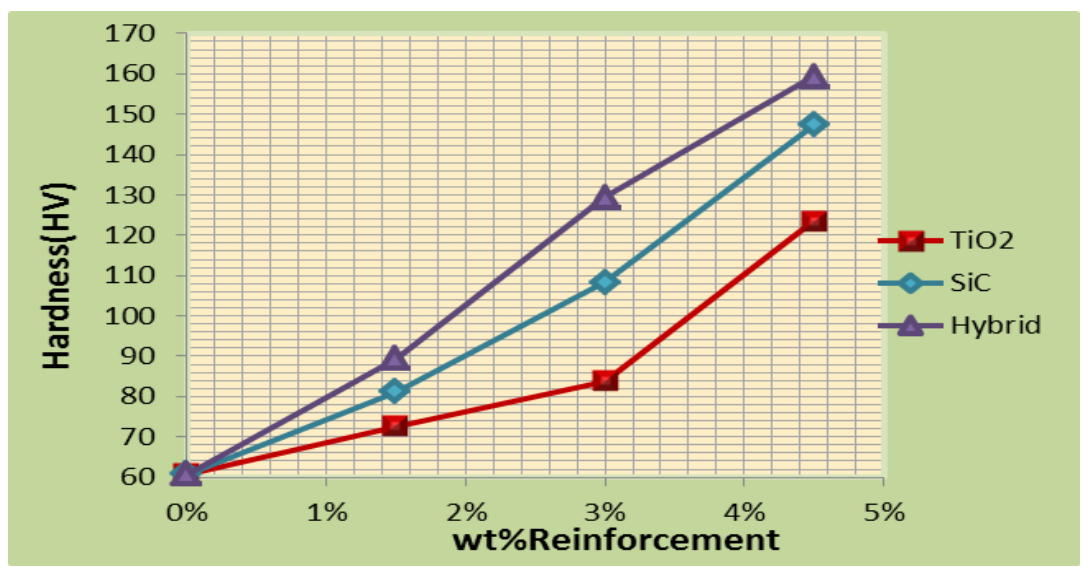

Fig(30) The relationship between hardness and reinforcements. 